\title{
The Implication of Climate Signal for Precipitation in the Heihe River Basin, Northwest China
}

\author{
Fei Wang and Jun Niu \\ Center for Agricultural Water Research in China, China Agricultural University, Beijing 100083, China \\ Correspondence should be addressed to Jun Niu; niuj@cau.edu.cn
}

Received 26 February 2016; Revised 4 May 2016; Accepted 1 June 2016

Academic Editor: Hung Soo Kim

Copyright (C) 2016 F. Wang and J. Niu. This is an open access article distributed under the Creative Commons Attribution License, which permits unrestricted use, distribution, and reproduction in any medium, provided the original work is properly cited.

\begin{abstract}
This paper studies the stochastic dynamic variability of precipitation, for the upper, middle, and lower reaches of the Heihe River basin in Northwest China, by employing Mann-Kendall statistic, Pettitt test, and wavelet transform methods. The possible associations with three prominent climatic patterns, El Niño-Southern Oscillation (ENSO), Artic Oscillation (AO), and Indian Ocean Dipole (IOD), are examined by using multiscale wavelet coherence method. No significant trend is identified for the interannual precipitation variability. However, about 2-year significant variability is detected for the lower reach of the Heihe River basin, and this dominating precipitation variability is essentially depicted by AO. The possible influences of ENSO are exerted on long-term timescale, $8-16$ years. The obtained knowledge is helpful for the predications of extreme hydroclimatological events and better reservoir operations for regional water resources.
\end{abstract}

\section{Introduction}

The Heihe River in Northwest China (see Figure 1) is the second largest inland river with the length of $821 \mathrm{~km}$, and total area of the basin about $160,000 \mathrm{~km}^{2}$. The river is divided into three sections with two control streamflow dams, namely, Yingluoxia and Zhengyixia. The upstream originates from the Qilian Mountains and the downstream terminates in Juyanhai Lake [1]. The long-term average precipitation decreases from 200 and $500 \mathrm{~mm} /$ year in the upper mountain area to between 50 and $200 \mathrm{~mm}$ /year in the lower desert area [2]. The potential evaporation difference between the upper reach and lower reach is about $3000 \mathrm{~mm} /$ year [3]. The middle reach of the Heihe River basin is a flat oasis area, which accommodates $98 \%$ agricultural lands of the whole river basin. Due to the limited precipitation amount, both river flow diversion and groundwater withdrawn are performed to fulfill the large requirement of crop irrigations. These activities significantly affect the regional ecology system, especially for the downstream region. Therefore, the predictions of local hydroclimate events are of high importance to devise better water resources management and adaptation strategies.

The abundance and deficit of precipitation are the coupling effects of local random processes and the possible influences of large-scale climate patterns under the context of complex land-ocean-atmospheric mechanisms [4-6]. Among it, the implications of large-scale climate anomalies for regional terrestrial hydrological processes are wildly studied in the circumference of major oceans. The influences of ENSO on land surface fluxes over the North America show that the delay responses range from a month to a season or longer [7]. The influences of ENSO on streamflow variability are found for the Yangtze River in China [8]. Guan and Yamagata [9] report the implications of IOD on the precipitation patterns in the East Asia. The interdecadal abrupt changes of $\mathrm{AO}$ and their possible impacts on summer monsoon rainfall in East Asia are revealed in the study of Ju et al. [10]. The impacts of $\mathrm{AO}$ on precipitation and temperature in Northern Eurasia are studied by Kryzhov and Gorelits [11]. Given these external influences found, this paper aims to detect the triggers for the dominant precipitation variability in the Heihe River basin, in terms of the implications of prominent climatic patterns.

In this paper, several stochastic methods, including the Mann-Kendall trend analysis, change point test, Pettitt test, and the wavelet transform, are employed to examine the precipitation characteristics in the Heihe River basin. The relations between the precipitation over the basin and major 


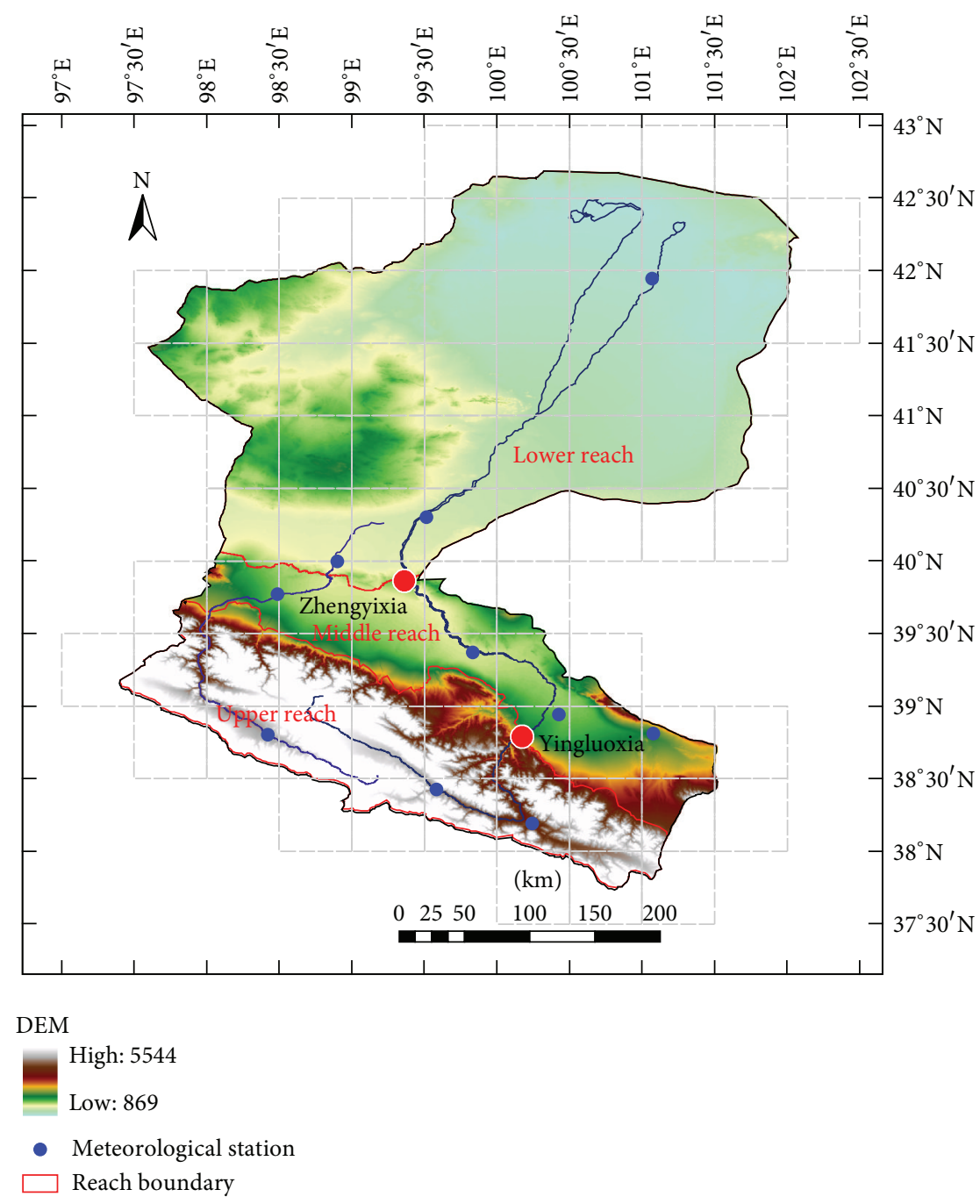

FIGURE 1: The study area with 0.5 -degree grid cells.

climate signals at multitimescales are further explored by using wavelet coherence analysis. The methods and data adopted in the present study are first offered in Sections 2 and 3, respectively. The statistical dynamical variability of precipitation, the possible influences of the ENSO from the Pacific Ocean, the AO from the Arctic Ocean, and the IOD from the Indian Ocean are discussed in Section 4. The conclusions are given in Section 5.

\section{Methods}

2.1. Trend Analysis. The Mann-Kendall trend test is a simple nonparametric statistical method, and the test is not interfered with by outliners $[12,13]$. For a long-term series $X$ which has $n$ samples, the test statistic $S$ can be calculated by the following formula:

$$
S=\sum_{i=1}^{n-1} \sum_{j=i+1}^{n} \operatorname{sgn}\left(x_{i}-x_{j}\right)
$$

where $x_{i}$ and $x_{j}$ are the values in years $i$ and $j, i>j ; n$ is the length of the series, and $\operatorname{sgn}\left(x_{i}-x_{j}\right)$ is a characterization of the function

$$
\operatorname{sgn}(\theta)= \begin{cases}+1, & \theta>0, \\ 0, & \theta=0, \\ -1, & \theta<0 .\end{cases}
$$

The normally distributed statistic $Z_{c}$ is given as

$$
Z_{c}=\left\{\begin{array}{cl}
\frac{S-1}{\sqrt{\operatorname{var}(S)},} & S>0, \\
0, & S=0, \\
\frac{S+1}{\sqrt{\operatorname{var}(S)}}, & S<0,
\end{array}\right.
$$

$\operatorname{var}(S)$

$$
=\frac{1}{18}\left[n(n-1)(2 n+5)-\sum_{p=1}^{q} t_{p}\left(t_{p}-1\right)\left(2 t_{p}+5\right)\right],
$$


where $q$ is the number of the tied group and $t_{p}$ is the number of data in $p$.

A significant trend is identified when $\left|Z_{c}\right|>Z_{1-\alpha / 2}$. Among it, $\alpha$ is the significance level of the test, and $Z_{1-\alpha / 2}$ is calculated according to the standard normal distribution function.

Meantime, Sen's slop is performed for the test comparison. Sen's slope of the monotonic trend is estimated as follows:

$$
\beta=\operatorname{Median}\left(\frac{x_{i}-x_{j}}{i-j}\right), \quad \forall j<i, 1 \leq j<i \leq n .
$$

A positive value of $\beta$ indicates a rising trend of the time series, and vice versa for the negative $\beta$.

2.2. Mann-Kendall Statistic. On the basis of Mann-Kendall trend test, the following statistics can be computed:

$$
U F_{k}=\frac{S_{k}-E\left(S_{k}\right)}{\sqrt{\operatorname{var}\left(S_{k}\right)}}, \quad(k=1,2, \ldots, n),
$$

where $E\left(S_{k}\right)$ is the mean of $S_{k}$ and $\operatorname{var}\left(S_{k}\right)$ is the variance of $S_{k}$.

Repeat the above calculation process at the reversed long-time series $\left\{X_{n}, X_{n-1}, \ldots, X_{1}\right\}$, and then obtain another statistical variable:

$$
U B_{k}=-U F_{k} \text {. }
$$

If the curves of $U B_{k}$ and $U F_{k}$ have an intersection point and the value of $U$ at this point satisfies $|U|<1.96$, then the point can be regarded as a change point, with a significance level $\alpha$ of 0.05 .

2.3. Pettitt Test. The Pettitt test [14] is another common method to detect long-term change point of an analyzed time series. This method is based on a statistical function $U_{t, n}$. Assume $t$ is the most likely change point. Then the time series $\left\{X_{1}, X_{2}, \ldots, X_{n}\right\}$ is divided into two samples at time $t$, that is, $\left\{X_{1}, X_{2}, \ldots, X_{t}\right\}$ and $\left\{X_{t+1}, X_{t+2}, \ldots, X_{n}\right\}$. For the continuous sequence, $U_{t, n}$ can be calculated by the following formula:

$$
U_{t, n}=U_{t-1, n}+\sum_{i=1}^{n} \operatorname{sgn}\left(x_{t}-x_{j}\right), \quad t=2,3, \ldots, n .
$$

If there is a change point of the long-term sequence, the value of $\left|U_{t}\right|$ would increase and then decrease. And the point where the value of $\left|U_{t}\right|$ is maximum can be considered as the most significant change point. Otherwise, the value of $\left|U_{t}\right|$ will increase continually. The formula of $k(t)$ and the approximated significance probability $P$ of the change point is as follows:

$$
\begin{aligned}
k(t) & =\max _{1 \leq t \leq n}\left|U_{t, n}\right|, \\
P & \cong 2 \exp \left\{\frac{-6\left(K_{n}\right)^{2}}{\left(n^{3}+n^{2}\right)}\right\} .
\end{aligned}
$$

Assuming a significance level of $\alpha$, when probability $p(t)$ is larger than $(1-\alpha)$, the change point can be identified as statistically significant at time $t$.
2.4. Wavelet Analysis. Wavelet analysis is a powerful tool to examine the variability evolution at different timescales, since wavelets display variability in both time and frequency domain [15-17]. The continuous wavelet transform of a time series $x_{n}(n=0, \ldots, N-1)$ is defined as the convolution of $x_{n}$ with a scaled and translated wavelet $\psi_{0}(\eta)$ :

$$
W_{n}(\xi)=\sum_{\gamma=0}^{N-1} x_{\gamma} \psi^{*}\left[\frac{(\gamma-n) \delta t}{\xi}\right]
$$

where $*$ indicates the complex conjugate, $\xi$ is the wavelet scale for varying the window width as multiples of the lowest frequency $(1 / \delta t$, in which $\delta t$ is the time interval), and $\gamma$ is the translation parameter to shift the wavelet along the time. The mother wavelet (i.e., Morlet wavelet in this study), $\psi_{0}(\eta)$, which depends on a nondimensional "time" parameter $\eta$, is defined as follows [18]:

$$
\psi_{0}(\eta)=\pi^{-1 / 4} e^{i \omega_{0} \eta} e^{-\eta^{2} / 2}
$$

where $\omega_{0}$ is the nondimensional frequency. The local wavelet power spectrum is defined as $\left|W_{n}(\xi, \gamma)\right|^{2}$, which gives a local measure of the variance of the analyzed time series at each scale and at each time.

A global wavelet spectrum, $\bar{W}^{2}(\xi)$, is defined by averaging all the local wavelet spectra:

$$
\bar{W}^{2}(\xi)=\frac{1}{N} \sum_{n=0}^{N-1}\left|W_{n}(\xi)\right|^{2} \text {. }
$$

The wavelet coherence analysis is capable of identifying regions in time-frequency domain where the two time series covary. Following Torrence and Webster [19], the coherence phase is defined as $\tan ^{-1}$ [imaginary part of $\left\{W_{n}^{X Y}(s)\right\} /$ real part of $\left.\left\{W_{n}^{X Y}(s)\right\}\right]$, and the wavelet coherence of the two time series is given as follows:

$$
R_{n}^{2}(s)=\frac{\left|S\left(s^{-1} W_{n}^{X Y}(s)\right)\right|^{2}}{S\left(s^{-1}\left|W_{n}^{X}(s)\right|^{2}\right) \cdot S\left(s^{-1}\left|W_{n}^{Y}(s)\right|^{2}\right)},
$$

where $S$ is a smoothing operator, given by [20]

$$
S(W)=S_{\text {scale }}\left(S_{\text {time }}\left(W_{n}(s)\right)\right) \text {, }
$$

where $S_{\text {scale }}$ is the smoothing along the wavelet scale axis and $S_{\text {time }}$ is the smoothing in time. A suitable smoothing operator for the Morlet wavelet is provided by Torrence and Webster [19] as follows:

$$
\begin{gathered}
\left.S_{\text {time }}(W)\right|_{s}=\left.\left(W_{n}(s) * c_{1}^{-t^{2} / 2 s^{2}}\right)\right|_{s}, \\
\left.S_{\text {scale }}(W)\right|_{n}=\left.\left(W_{n}(s) * c_{2} \pi(0.6 s)\right)\right|_{n},
\end{gathered}
$$

where $c_{1}$ and $c_{2}$ are normalization constants and $\pi$ is the rectangle function. The factor 0.6 is the decorrelation length of empirically determined scale for the Morlet wavelet [18]. 


\section{Data}

3.1. Precipitation Data. There are only ten meteorological stations, shown in Figure 1, within the Heihe River basin studied, which may not sufficiently describe the spatial distribution of the precipitation in the whole basin. Therefore, the spatially distributed data are preferred for the relevant analysis. The precipitation data we selected are extracted from the global 0.5-degree gridded meteorological forcing data set (available at http://www.hydro.washington.edu/). There are 81 grid cells with the spatial resolution 0.5 degrees for the whole basin during the period of 1950-2006. The systematic bias of the gridding data is adjusted with gauge precipitation using the method described in Adam and Lettenmaier [21]. The orographic effects are also corrected as described in Adam et al. [22]. The comparisons between the observation data from 10 metrological stations and the data in the grid cells where the meteorological station is located show an acceptable agreement with the average $R^{2}$ (coefficient of determination) value 0.76 , the average NSE (Nash-Sutcliffe Efficiency coefficient) value 0.54 , and the average RMSE (Root Mean Square Error) value $10.62 \mathrm{~mm}$.

The monthly precipitation is adopted, derived from the daily scale data, to be compatible with the large-scale climate signal data. With due consideration to the regional hydrological factors and local water resources activities, the precipitation data over the period of 1950-2006 are spatially aggregated for the three sections, that is, the upper, middle, and lower reaches of the Heihe River basin. Among it, (1) the precipitation from the grid cells in each section is weighted by the fraction of the grid cell within the study basin and then (2) the total precipitation is divided by the total fractions.

3.2. Climate Signals. Three major climatic signals, El NiñoSouthern Oscillation (ENSO), Artic Oscillation (AO), and Indian Ocean Dipole (IOD), possibly influencing Northwest China, are screened for the implication analysis with the precipitation in the Heihe River basin. The Niño-3.4 $\left(5^{\circ} \mathrm{N}-5^{\circ} \mathrm{S}\right.$, $170^{\circ}-120^{\circ} \mathrm{W}$ ) sea surface temperature (SST) and AO index data are obtained from the Earth System Research Laboratory in the National Oceanic and Atmospheric Administration (NOAA) (available at http://www.esrl.noaa.gov/) for the 57year period (1950-2006). The IOD anomalies during the period are from Low-latitude Climate Prediction Research in Japan Marine Science and Technology Center (available at http://www.jamstec.go.jp/).

\section{Results and Discussions}

4.1. Analysis of Annual Trend and Change Points. To give an overview of precipitation characteristics over the upper, middle, and lower reaches of the Heihe River basin, the basis statistics of the annual and monthly precipitation data for the period of 1950-2006 are listed in Table 1. It is observed that the precipitation amount decreases from upstream to downstream along the river. Interannual and seasonal variability are more obvious for the precipitation in the lower reach reflected by the values of the coefficient of variance. Positive skewness is found for all three reaches, which means that
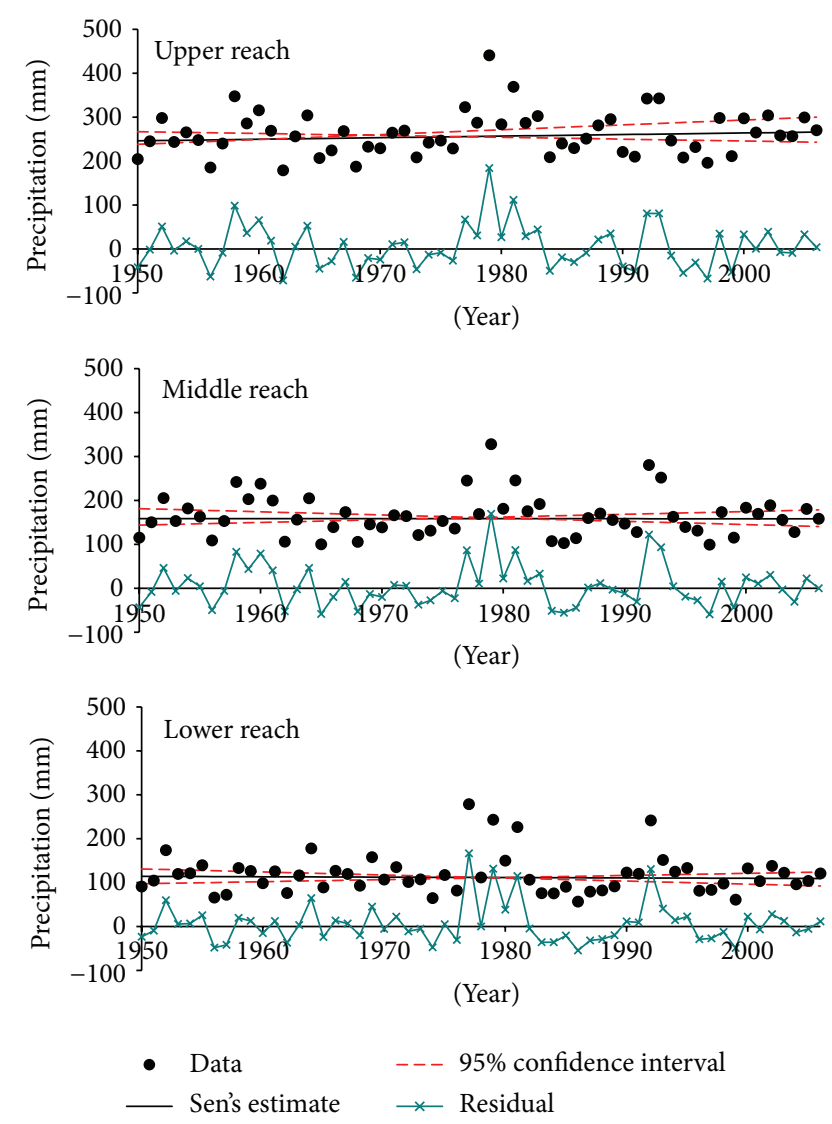

FIGURE 2: Sen's slop estimate for annual precipitation in the Heihe River basin.

there are more small values of precipitation amount among all annual/monthly events. The Mann-Kendall trend analysis is performed on the annual precipitation data for 57 years. The $Z$ values for the upper, middle, and lower reaches are $1.07,-0.09$, and -0.32 , respectively. These indicate that the precipitation has a slightly increased trend in the upstream mountain area and decrease trend for both the agricultural area in the middle reach and the desert area in the lower reach of the Heihe River. Figure 2 shows the trend testing using Sen's slop estimation, with the related residues. The three fitted lines are all within the 95\% confidence level, which indicates the effectiveness of the linear trend assumed for the annual data. However, as all the slope values of the linear trend do not pass the significance testing, the increase/decrease trends of precipitation are actually weak in the Heihe River basin for the period studied.

The change point results of nonparametric MK analysis are shown in Figure 3 for the precipitation over the period of 1950-2006. No significant increase or decrease trend is observed as all values are basically within the $95 \%$ confidence levels. It is observed that there are several cross points between the progressive and retrograde $Z$ series for the upper reach in Figure 3. Among them, the most obvious one is in 1976, and the decrease trend is changed into the increase trend in this point. The Pettitt change point analysis is also 
TABLE 1: The basic stochastic characteristics of annual/monthly precipitation in Heihe River basin.

\begin{tabular}{lccccc}
\hline & Mean $(\mathrm{mm})$ & Max. $(\mathrm{mm})$ & Min. $(\mathrm{mm})$ & Coefficient of variation & Skewness \\
\hline Upper reach & $262.36 / 21.86$ & $440.66 / 115.49$ & $179.11 / 0.09$ & $0.19 / 1.08$ & $0.93 / 1.22$ \\
Middle reach & $164.82 / 13.74$ & $328.03 / 94.36$ & $99.19 / 0$ & $0.28 / 1.16$ & $1.13 / 1.95$ \\
Lower reach & $118.32 / 9.86$ & $278.48 / 99.90$ & $56.87 / 0$ & $0.38 / 1.32$ & $1.67 / 2.63$ \\
\hline
\end{tabular}
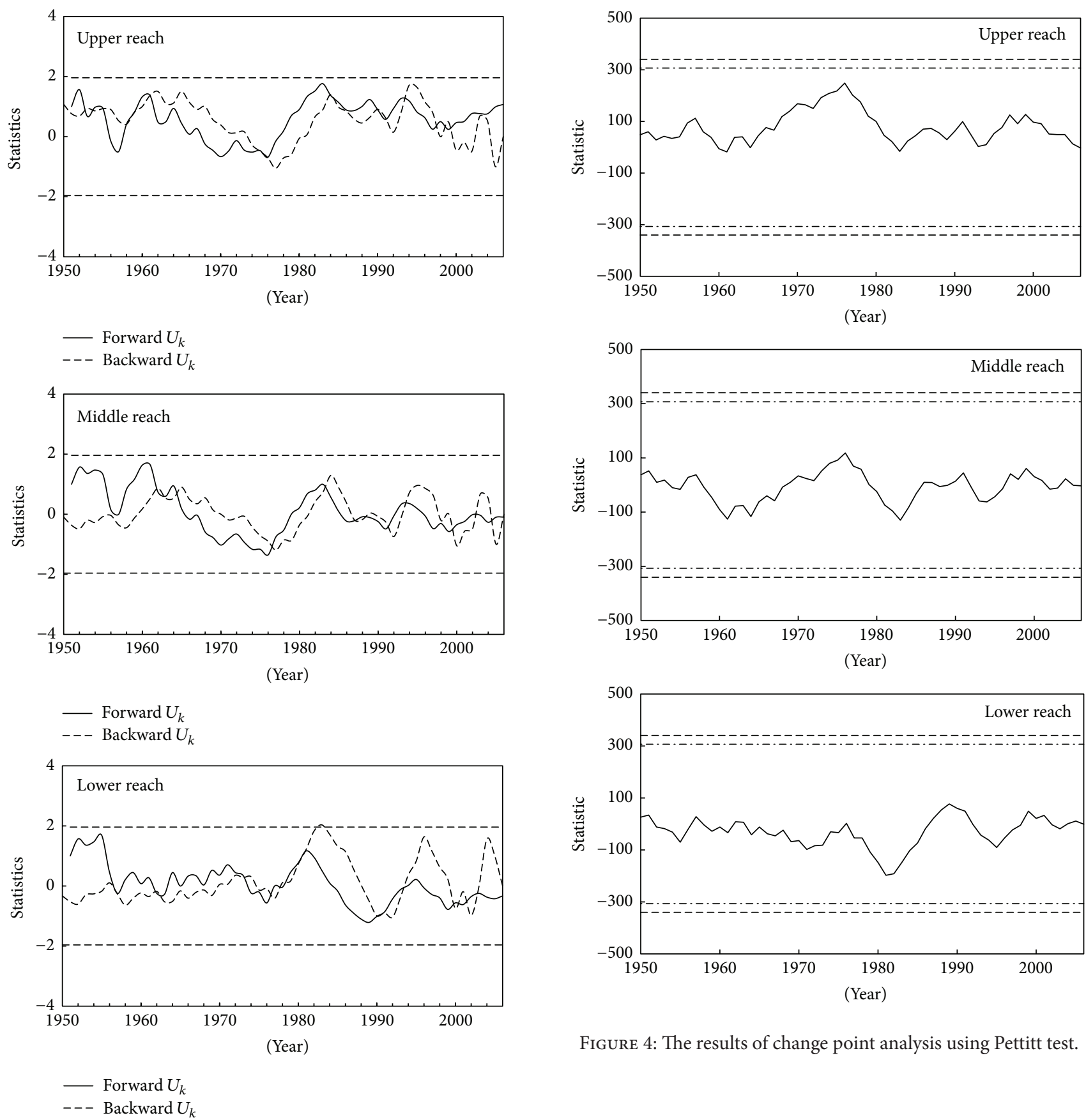

FIgURE 4: The results of change point analysis using Pettitt test.

FIGURE 3: The results of MK change point analysis.

employed for the robustness purpose. The results of the Pettitt analysis also show the turning point in 1976, as shown in Figure 4. The similar results about the trend changing

around 1976 are obtained for the middle reach precipitation in Figures 3 and 4. For the precipitation in lower reach, the turning point is found in 1981 in both Figures 3 and 4, which is also not significant at $95 \%$ confidence level. The increase trend is changed into the decrease trend after this year. 

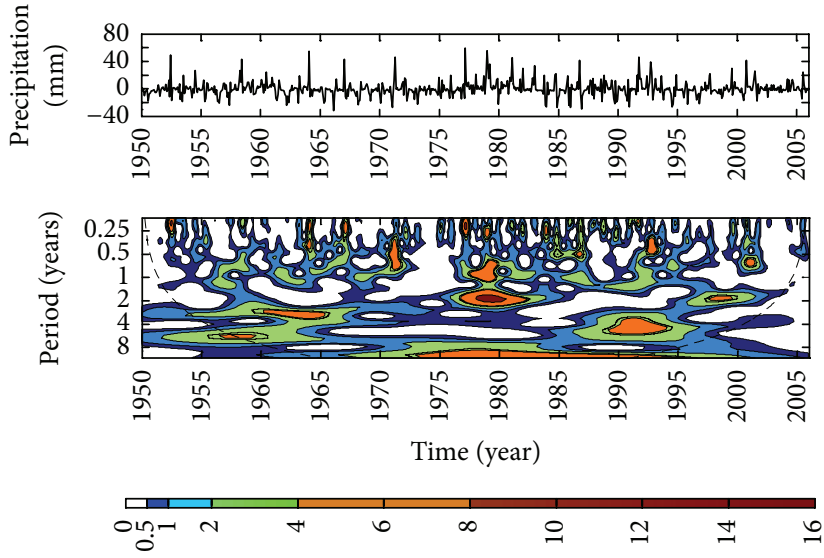

(a)
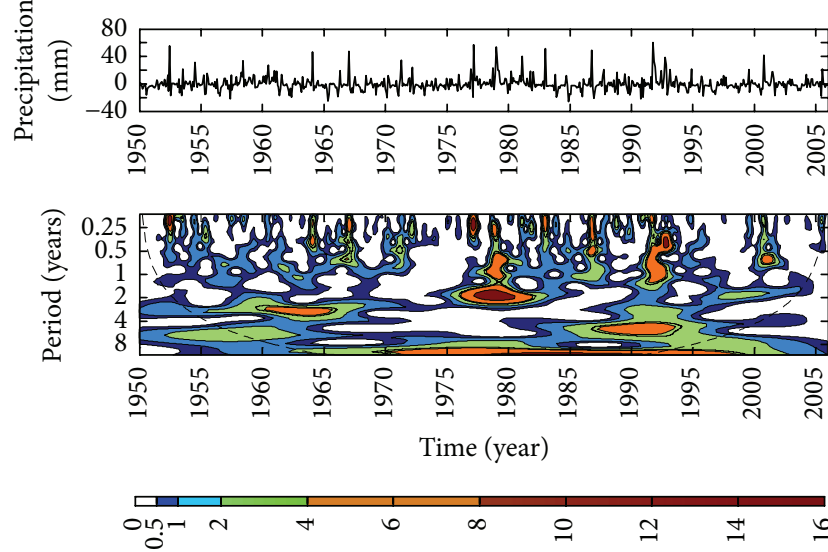

(b)
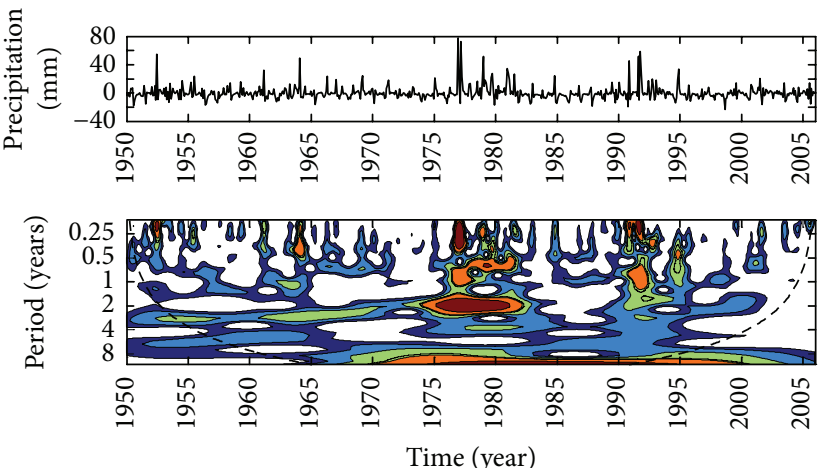

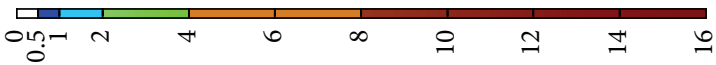

(c)

Figure 5: (a) The monthly precipitation anomaly time series in the upper stream of the Heihe River (upper panel) and its local wavelet power spectrum (lower panel) using the Morlet wavelet, normalized by $1 / \sigma^{2}\left(\sigma^{2}=126.45 \mathrm{~mm}^{2}\right)$. The dashed curve depicts the cone of influence beyond which the edge effects become important. The shaded contours are at normalized variances of $0.5,1,2,4$, and 8 . The contour closes regions of greater than $95 \%$ confidence for a red-noise process with a lag- 1 coefficient $\alpha$ of 0.10 . (b) Same as (a), but for the middle reach, with $\sigma^{2}=110.09 \mathrm{~mm}^{2}$ and $\alpha=0.09$. (c) Same as (a), but for the lower reach, with $\sigma^{2}=95.96 \mathrm{~mm}^{2}$ and $\alpha=0.09$.

4.2. Wavelet Analysis of Monthly Precipitation. To further reveal the precipitation structures in the Heihe River basin, the Morlet wavelet transform is performed on the monthly precipitation anomalies (obtained by removing monthly mean for 1950-2006). Figure 5(a) shows the local wavelet power spectrum for the precipitation in the upper reach. The wavelet power is broadly distributed within the timefrequency domain. The higher power is found for different timescales at certain time positions. The abnormal precipitation events are identified during 1960-1965 and around 1970 and 1975-1995. The significant variabilities within the regions above $95 \%$ confidence level (about $4 \sigma^{2}$ ) demonstrated that the noticeable precipitation power is during 1980-1985 in the 2-4-year band, within 1975-1985 in 0.5-2 year-band, and within 1990-1995 in the 2-8-year band. The similar wavelet power distribution is observed for the monthly precipitation anomalies in the middle reach of the Heihe River, with more significant variability during 1990-1995 in 0.25-2-year band in Figure 5(b). The noticeable precipitation variability in the lower reach of the Heihe River basin is the largest amount of precipitation during 1975-1983 within the 4-year band, as shown in Figure 5(c). Several significant precipitation events at short timescale less than 0.5 -year period are also observed for years 1952, 1964, 1977, and 1992.

The global wavelet power spectrum summarizes the scale-dependent variability in Figure 6 . The highest precipitation variability in the lower reach of the Heihe River basin is detected around 2-year band, which is above the 95\% confidence level. Less randomness of the underlying precipitation processes, which may be in the teleconnection with climate patterns, is indicated. Apart from the 2year timescale, significant variability is also found for the timescales larger than 8 years. However, due to the length of the analyzed time series, the interpretation for the variability features over these timescales is not for the whole 57-year period due to the edge effects in the performance of wavelet analysis.

4.3. Implications of Climate Signals. To find the possible triggers for the significant variabilities observed in Section 4.2, 


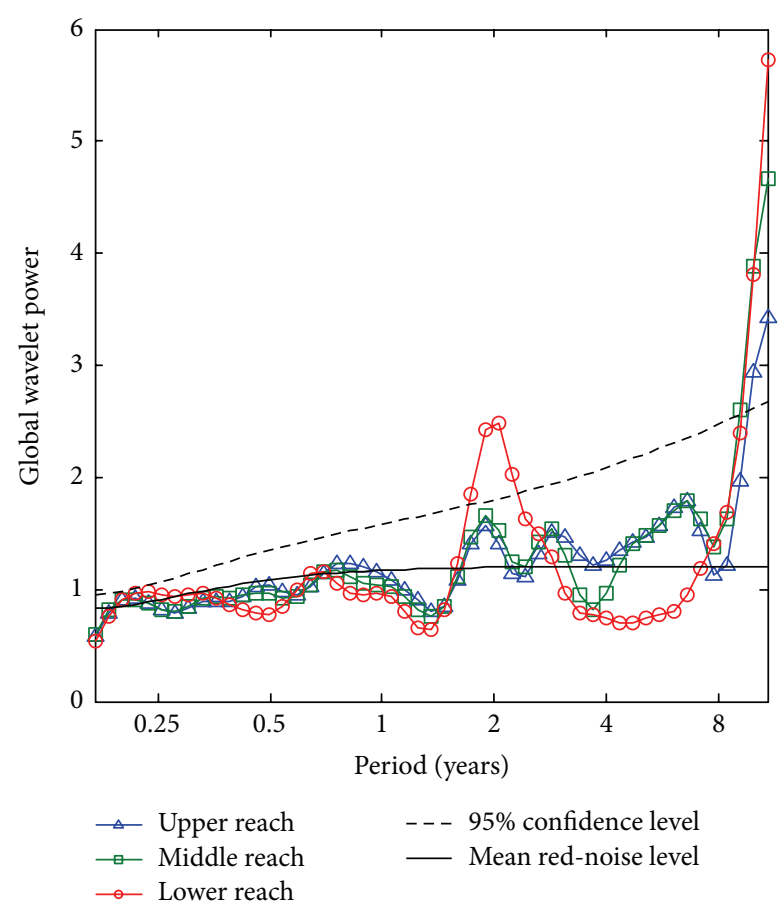

FIGURE 6: Global wavelet power spectrum for the monthly precipitation anomalies in the upper, middle, and lower reaches of the Heihe River basin. The lower solid line is the mean read-noise spectrum, while the upper dashed line is the $95 \%$ confidence level for the global wavelet spectrum by assuming a red-noise process with the mean lag-1 autocorrelation of 0.093 .

the linkages between precipitation in the Heihe River basin and large-scale climatic signals are examined by employing the wavelet coherence method. Figure 7 shows the wavelet coherence results between precipitation and ENSO (upper panel), AO (middle panel), and IOD (lower panel). For the influences of ENSO, the high power at the $>95 \%$ confidence level is mainly observed above 4 -year timescale for the upper and lower reaches of the Heihe River basin and above 8-year timescale for the lower reach.

There are more coherence power between precipitation and $\mathrm{AO}$ within 8-year timescale. The noticeable region with high wavelet coherence during 1960-1965 around 2-4-year band is detected for the upper and middle reaches of the basin. These are consistent with the wavelet transform results shown in Figure 5, which indicate that the high variability precipitation around 2-4-year band during 1960-1965 may be trigged by the $\mathrm{AO}$ climate signal. The same link also found for the period 1990-1995 around 4-8-year band seems to indicate the clear link between $\mathrm{AO}$ and precipitation in the upper and middle reaches of the basin.

Zheng et al. [23] reported that AO played an important role in the changes of the East Asian winter monsoon, the pressure, and wind fields in East Asia. The East Asian winter monsoon and Mongolia high tend to be weaker in the high index of $\mathrm{AO}$, and the Westerlies in spring dominates the zonal circulation. Mongolia and North China locate in the warmer sector of blocking high of Lake Baikal, resulting in weaker northwest wind. These situations are generally opposite during the period of the low index of AO. All these factors are directly or indirectly related to the moisture transmission and contribute to the regional precipitation variability in Heihe River basin. In addition, Cheng et al. [24] also statistically found the possible influences of AO on precipitation in Henan Province in North China which appeared at the long-term timescales.

The coherence power is less detected between the precipitation in Heihe River basin and IOD signal, as shown in Figure 7. The antiphase relations are found around 1990 with 2-4-year band for precipitation in both upper and middle reaches. The close antiphase relationship is also found around 1960 within 4-8-year band for the lower reach of the river basin.

Although some significant precipitation variability for the upper and middle reaches can be effectively explained by the variations of $\mathrm{AO}$ signal, the high precipitation variability during 1975-1980 around 2-4-year band, for the lower reach of the Heihe River basin shown in Figure 5, can be only partly explained. This is ambiguous and attributed to the complex correlations between precipitation in the lower reach and climate signals, which need further significant evidences.

\section{Conclusions}

The significant variability (the trend or change points) may be not observed on the annual precipitation data, like the case in the Heihe River basin for the period of 1950-2006. However, the dominant variability of precipitation can be found at other different timescales, as demonstrated in the present study. The wavelet transform exhibits the variability power at a time-frequency domain, which enables us to find the significant variabilities for different timescales during subperiods. A larger than $95 \%$ confidence level variability is detected around 2-year timescale for the lower reach of the Heihe River basin.

The significant variability of precipitation identified at low-frequency timescales is possibly connected with climate signals. The wavelet coherence results between regional precipitation and climatic patterns demonstrate that the precipitation variability around 2-4-year band is basically depicted by AO signal. The precipitation variability for longer timescales, 8-16-year band, are connected with ENSO signal. There are less covary processes between regional precipitation and IOD.

The predictions of climate signals from major oceans are possible with a certain leading time. These correlation findings are helpful in informing early warning for precipitation evolutions, when the predicted climate signals are available. However, the complex correlations between regional precipitation and climate signals need to be further investigated, as the cross-effects for different climate signals may exist, which requires more understanding of the teleconnection mechanisms.

\section{Competing Interests}

The authors declare that they have no competing interests. 

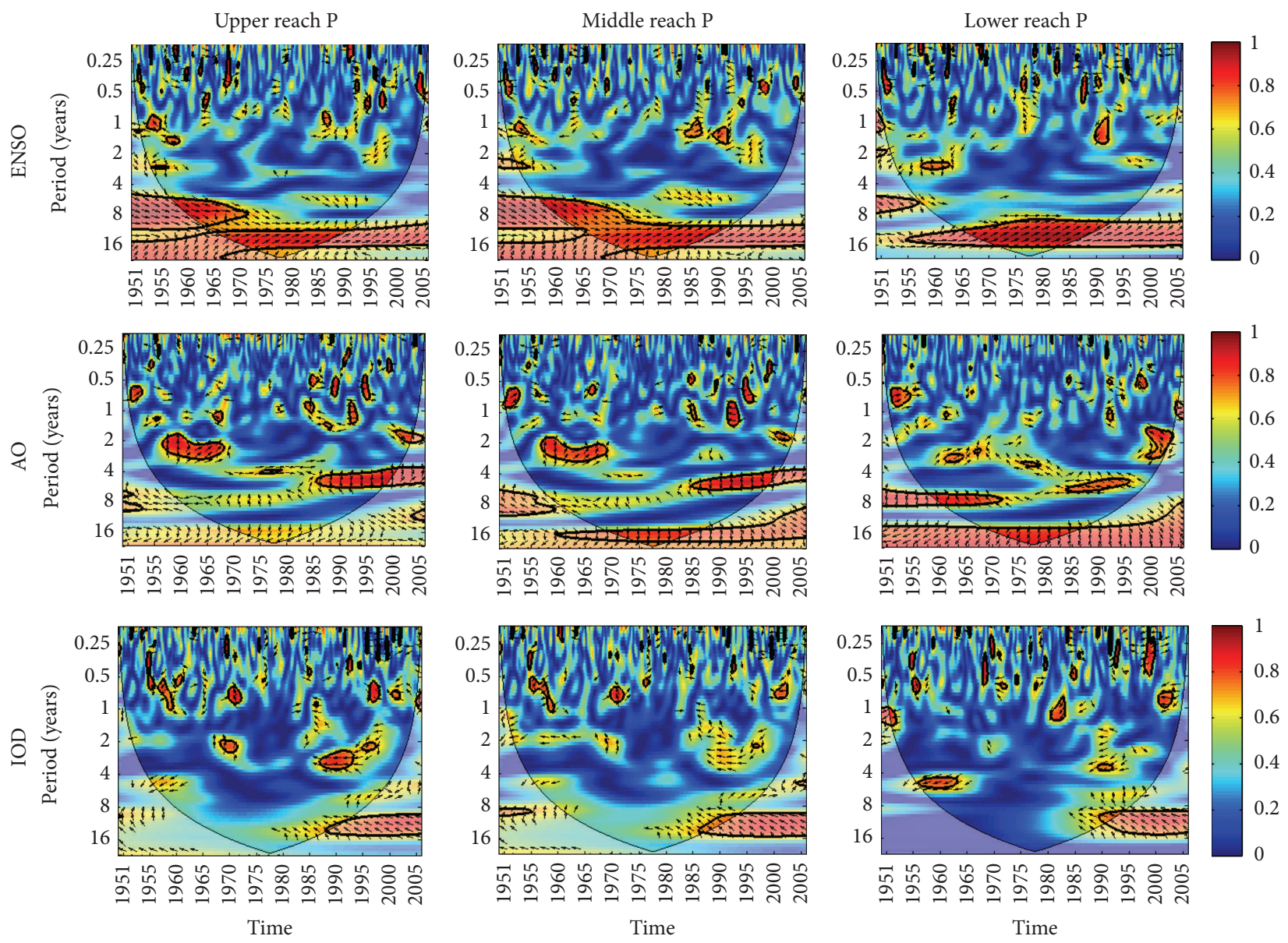

FIGURE 7: Wavelet coherence between climate signal (ENSO, AO, and IOD) and precipitation (in the upper, middle, and lower reaches) of the Heihe River basin. The thick contour indicates the $95 \%$ confidence level against red noise. The relative phase relationship is shown as arrows (with in-phase pointing right, antiphase pointing left, ENSO leading precipitation by $90^{\circ}$ pointing straight down, and precipitation leading ENSO pointing straight up).

\section{Acknowledgments}

The authors are grateful to the financial support provided by the National Natural Science Foundation of China (91425302, 51309198) and Chinese Universities Scientific Fund (2015QC044).

\section{References}

[1] G. Cheng, "Study on the sustainable development in Heihe River Watershed from the view of ecological economics," Journal of Glaciology Geocryology, vol. 24, no. 4, pp. 335-344, 2002 (Chinese).

[2] C. Zang and J. Liu, "Trend analysis for the flows of green and blue water in the Heihe River basin, northwestern China," Journal of Hydrology, vol. 502, pp. 27-36, 2013.

[3] Z. L. Li, Runoff simulation in the upper reaches of Heihe river basin and uncertainty analysis in hydrological modeling [Ph.D. dissertation], Beijing Normal University, Beijing, China, 2009 (Chinese).

[4] P. Kumar, "Role of coherent structures in the stochasticdynamic variability of precipitation," Journal of Geophysical Research Atmospheres, vol. 101, no. 21, pp. 26393-26404, 1996.
[5] L.-T. Zhou, C.-Y. Tam, W. Zhou, and J. C. L. Chan, "Influence of South China Sea SST and the ENSO on winter rainfall over South China," Advances in Atmospheric Sciences, vol. 27, no. 4, pp. 832-844, 2010.

[6] J. Niu and J. Chen, "Terrestrial hydrological responses to precipitation variability in Southwest China with emphasis on drought," Hydrological Sciences Journal, vol. 59, no. 2, pp. 325335, 2014.

[7] J. Chen and P. Kumar, "Role of terrestrial hydrologic memory in modulating ENSO impacts in North America," Journal of Climate, vol. 15, no. 24, pp. 3569-3585, 2002.

[8] Q. Zhang, C.-Y. Xu, T. Jiang, and Y. Wu, "Possible influence of ENSO on annual maximum streamflow of the Yangtze River, China," Journal of Hydrology, vol. 333, no. 2-4, pp. 265-274, 2007.

[9] Z. Guan and T. Yamagata, "The unusual summer of 1994 in East Asia: IOD teleconnections," Geophysical Research Letters, vol. 30, no. 1, pp. 5-1-5-4, 2003.

[10] J. Ju, J. Lü, J. Cao, and J. Ren, "Possible impacts of the Arctic Oscillation on the interdecadal variation of summer monsoon rainfall in East Asia," Advances in Atmospheric Sciences, vol. 22, no. 1, pp. 39-48, 2005. 
[11] V. N. Kryzhov and O. V. Gorelits, "The Arctic Oscillation and its impact on temperature and precipitation in Northern Eurasia in the 20th Century," Russian Meteorology and Hydrology, vol. 40, no. 11, pp. 711-721, 2015.

[12] H. B. Mann, "Nonparametric tests against trend," Econometrica, vol. 13, pp. 245-259, 1945.

[13] M. G. Kendall, Rank Correlation Measures, Charles Griffin, London, UK, 1975.

[14] A. N. Pettitt, "A non-parametric approach to the change-point problem," Journal of the Royal Statistical Society, Series C: Applied Statistics, vol. 28, no. 2, pp. 126-135, 1979.

[15] P. Kumar and E. Foufoula-Georgiou, "Wavelet analysis for geophysical applications," Reviews of Geophysics, vol. 35, no. 4, pp. 385-412, 1997.

[16] K.-M. Lau and Hengyi Weng, "Climate signal detection using wavelet transform: how to make a time series sing," Bulletin of the American Meteorological Society, vol. 76, no. 12, pp. 23912402, 1995.

[17] D. Labat, "Wavelet analyses in hydrology," in Advances in DataBased Approaches for Hydrologic Modeling and Forecasting, B. Sivakumar, R. Berndtsson, and B. hydrology, Eds., pp. 371-410, World Scientific Publishing Company, Singapore, 2010.

[18] C. Torrence and G. P. Compo, "A practical guide to wavelet analysis," Bulletin of the American Meteorological Society, vol. 79, no. 1, pp. 61-78, 1998.

[19] C. Torrence and P. J. Webster, "Interdecadal changes in the ENSO-monsoon system," Journal of Climate, vol. 12, no. 8, pp. 2679-2690, 1999.

[20] A. Grinsted, J. C. Moore, and S. Jevrejeva, "Application of the cross wavelet transform and wavelet coherence to geophysical times series," Nonlinear Processes in Geophysics, vol. 11, no. 5-6, pp. 561-566, 2004.

[21] J. C. Adam and D. P. Lettenmaier, "Adjustment of global gridded precipitation for systematic bias," Journal of Geophysical Research D: Atmospheres, vol. 108, no. 9, pp. 1-14, 2003.

[22] J. C. Adam, E. A. Clark, D. P. Lettenmaier, and E. F. Wood, "Correction of global precipitation products for orographic effects," Journal of Climate, vol. 19, no. 1, pp. 15-38, 2006.

[23] G. F. Zheng, G. P. Zhao, Z. G. Yao, Y. C. Sun, L. Na, and J. Q. Xu, "Effect of arctic oscillation on sandstorm in the eastern part of Northwest China," Journal of Desert Research, vol. 29, no. 3, pp. 551-557, 2009 (Chinese).

[24] B. Y. Cheng, W. G. Sun, J. F. Wang, W. L. Gu, and Y. Y. $\mathrm{Zhu}$, "Influence of arctic oscillation on precipitation of henan province," Meteorological and Environmental Sciences, vol. 30, no. 4, pp. 7-12, 2007 (Chinese). 

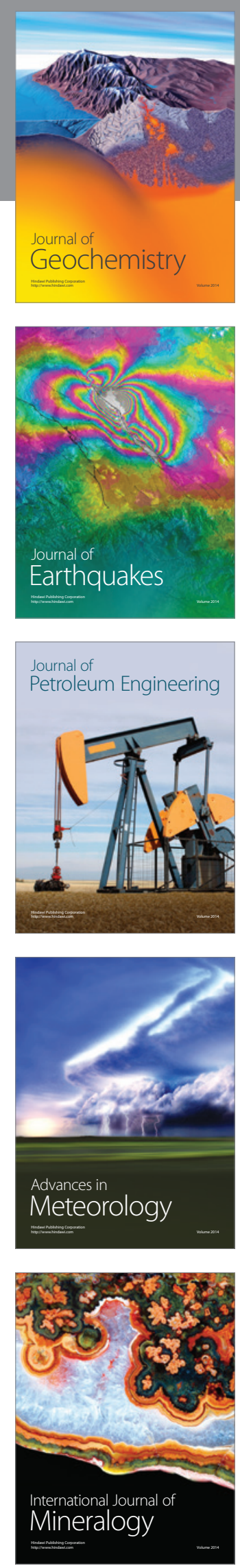
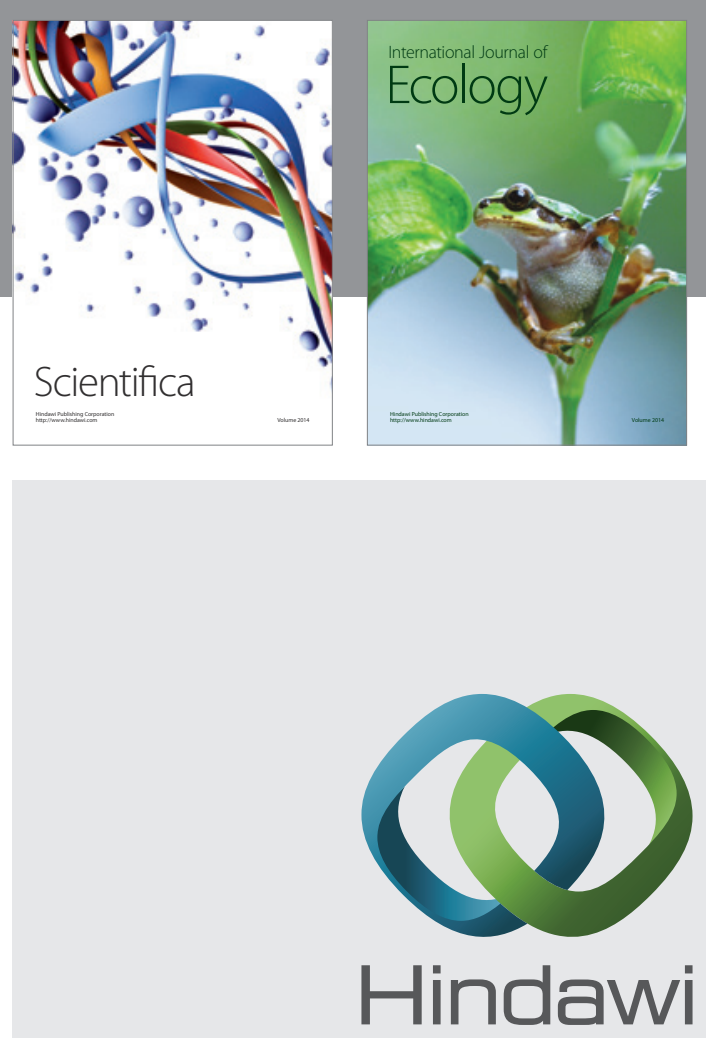

Submit your manuscripts at

http://www.hindawi.com
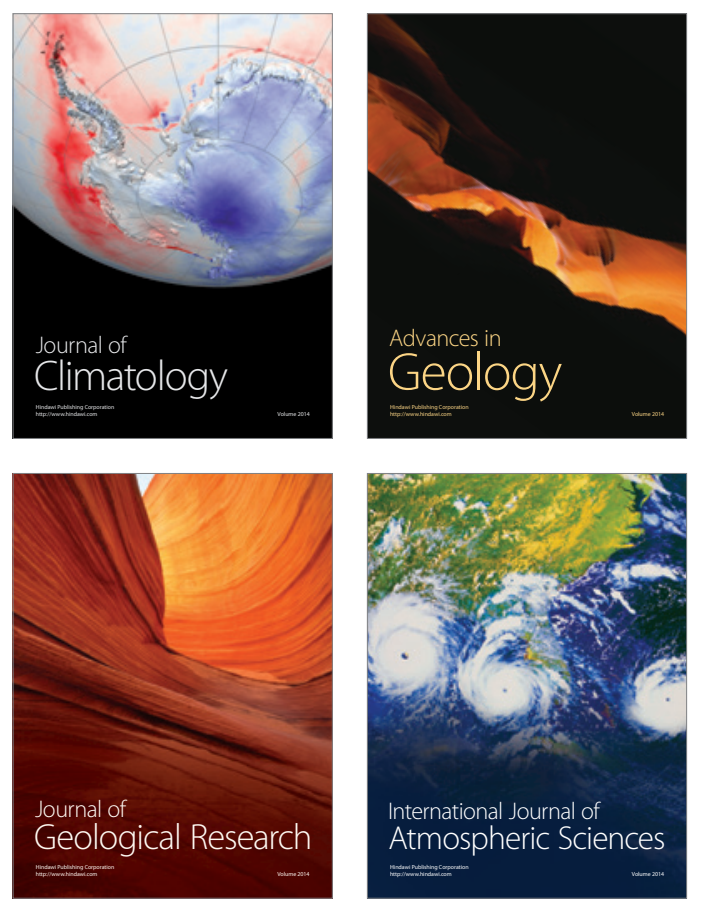

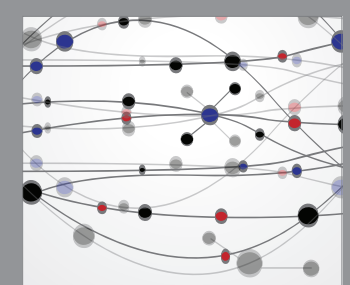

The Scientific

\section{World Journal}
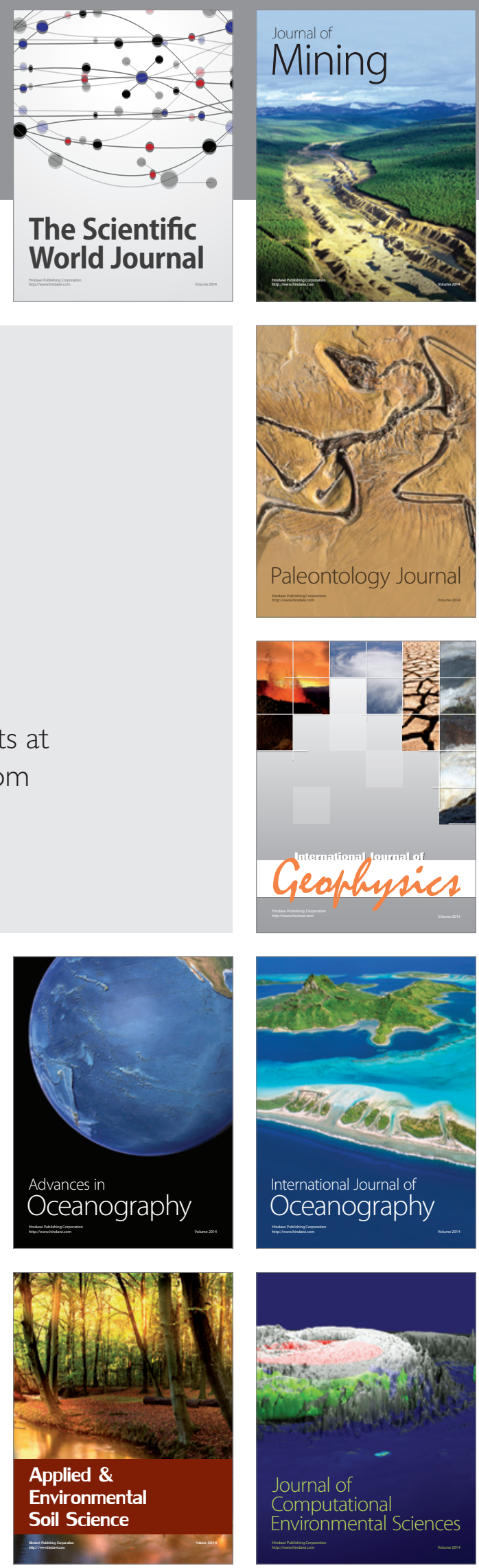